\title{
"Acá se admira todo mejorado": lisonja, identidad y corrupción en Arequipa (siglo XVIII)
}

\author{
César Félix Sánchez Martínez \\ Seminario Arquidiocesano de san Jerónimo
}

Entre las poesías cortesanas que se fijaron en carteles en diversos lugares públicos de Arequipa el 13 de junio de 1747 para celebrar, con gran solemnidad, la inauguración del monasterio de santa Rosa, se encontraba un soneto suficiente aunque un poco encorsetado, pero que mostraba algo más que la alegría barroca ceremonial usual en las festividades religiosas en los vastos reinos que componían la monarquía católica:
En dos bellas ciudades dividido,
el imperio de Jove sea admirado:
el orbe todo en una está postrado,
en la otra el mundo todo está erigido.
Allá los templos ruina han padecido,
acá se admira todo mejorado;
allá se muestra Dios tan enojado
cuanto se ostenta acá compadecido.
Pues, ¿no es el mismo numen poderoso
que igual virtud en todo el orbe encierra?
Sí, mas sus luces, aun pastor celoso,
dadas le tiene ya sobre la tierra;
destruya, pues, y postre riguroso,
siendo paces acá lo que allá guerra. ${ }^{1}$

Para no dejar ninguna duda de a qué se refería, el anónimo poeta atavió su tarja con el galano título de Antítesis o contraposición entre las dos ciudades de Lima y Arequipa; y por si fuera poco, el clérigo Ventura Travada -que transcribió en la última parte de su obra las "muchas poesías" escritas a la sazón por "los cisnes

\footnotetext{
1 Ventura Travada, Suelo de Arequipa convertido en cielo. Lima, edición facsimilar a cargo de Ignacio Prado Pastor, 1993 [1750], fols. 761-762. Se han modernizado la ortografía y la puntuación del soneto, al igual que en los textos siguientes. Agradezco por ello las orientaciones de los profesores Carlos Arrizabalaga y Crisanto Pérez, que han revisado la transcripción del original.
} 
del Caistro arequipense"- puso antes del soneto un epigrama latino mucho más elocuente: Templa cadunt illic; hic iam meliora resurgunt. / Divissum Imperium cum Jove praesul habes.

La ruina a la que se refieren los versos fue la producida por el devastador terremoto y tsunami que destruyeron Lima y el Callao el 28 de octubre del año anterior. Aquella permanente contraposición con Lima, tan importante para entender el discurso identitario arequipeño posterior, se manifestaba por primera vez y de una forma ciertamente extravagante; con esa extravagancia entre piadosa, ceremonial y casi dionisíaca en sordina que caracterizara a la cultura del barroco hispánico.

El mismo título de la extraña y fascinante crónica de Ventura Travada: Suelo de Arequipa convertido en cielo -escrita precisamente a raíz de la inauguración del monasterio- nos revela que los arequipenses de mediados del siglo XVIII ya demostraban poseer en cifra un elemento identitario fundamental para comprender el devenir histórico posterior de la Villahermosa: el regionalismo particularista respecto a Lima.

\section{A la conquista del espacio simbólico}

La erudición de raigambre platónica encontrará terreno fértil en el sur andino. Travada es el primer letrado arequipeño en citar al "divino Platón" y manifestar una acusada influencia del pensador ateniense, e iniciar una corriente filosófica local que fructificaría en dos siglos después en la obra filosófica de Jorge Polar y Víctor Andrés Belaunde. Ello y su estilo barroco eran las herramientas más adecuadas para intentar posicionar simbólicamente, con algo de tardanza, a una ciudad periférica pero pujante, en el contexto del discurso de la exaltación de la urbe criolla, en el que los letrados indianos venían empeñándose desde hacía casi un siglo. ${ }^{2}$

Aunque Travada sostiene no escribir "descripción poética, donde tiene puerta franca la ficción, sino histórica", ${ }^{3}$ el libro es mucho más que el texto fundacional de la historiografía de Arequipa; es un artefacto barroco escrito con una prosa galana -que haría que Francisco Mostajo, para nada un simpatizante de gongorismos ni casticismos, lo llamase poeta y que Guillermo Galdós considerase su obra como "la más brillante producción de la prosa arequipeña hasta nuestros días"-- ${ }^{4}$ signado por un rico simbolismo astrológico (las órdenes

2 Sobre su poética y las dimensiones filosóficas de la obra de Travada, cfr. César Félix SÁnchez Martínez, "Goloseado en las butillerías de la mitología: La poética neoplatónica y erudita de Ventura Travada en El suelo de Arequipa convertido en cielo (c. 1750)", Memoria y civilización, 21, 2018, pp. 1-21.

3 Ventura Travada, Suelo..., fol. 166.

$4 \quad \mathrm{Y}$ tal ponderación se ofrece estimando que "nos quedamos cortos al hacer tal limitación geográfica". Ver Guillermo Galdos Rodríguez, Cronistas e historiadores de Arequipa colonial. 
religiosas de Arequipa parangonadas con signos zodiacales), por pintorescas milagrerías y prodigios -visitantes de ultratumba, serpientes paganas parlantes, demonios que usan al Misti como puerta a sus dominios- $y$, por sobre todo, una exhibición de hiperbólico orgullo por las riquezas espirituales, intelectuales, agrícolas e incluso gastronómicas de Arequipa. Es famosa su mención a las "tres mil chicherías (...) donde se hace la más aplaudida chicha del reino" ${ }^{5}$

Tanto la obra de Travada como la Relación, de Jorge Juan y Antonio Ulloa, nos describen a la Arequipa de 1740 como una ciudad dinámica en una suerte de esplendor auroral, que se proyecta como una especie de Arequipa arquetípica, fundamental para comprender el imaginario regional posterior. Al calor de esta coyuntura expectante se fue labrando la cultura popular arequipeña, que casi un siglo después despertaría la perplejidad de Flora Tristán, que en algún momento se creyó transportada al mundo medieval. El tiempo estaba marcado por el año litúrgico y sus diversas celebraciones que matizaban con distinto color el paso de las estaciones y las distintas labores agrícolas que debían realizarse. Con ocasión de las procesiones de santos se exhibían variadas y pintorescas manifestaciones de la cultura popular criolla mediante danzas, sainetes teatrales, disfraces y recitaciones, que muchas veces abrevaban de los acervos tradicionales indígenas o africanos, así como los desfiles de gigantes y papahuevos, característicos de la fiesta tradicional española.

Resulta sorprendente, entonces, que tal periodo de la historia arequipeña (1725-1760) se encuentre poco estudiado, si lo comparamos con el periodo inmediatamente posterior, el de la llamada rebelión de los Pasquines, estudiado en el clásico libro homónimo de Guillermo Galdos Rodríguez (1967) y en Arequipa, en el paso de la Colonia a la República (1973), de Guillermo Zegarra Meneses. Quizá el prejuicio ideológico haya provocado que se preste mayor atención a los periodos de crisis posterior, y se exalte cuanto de emancipatorio se pudiese encontrar en esa coyuntura histórica -se llegó incluso al anacronismo-, antes que a este periodo de aparente estabilidad y riqueza de manifestaciones discursivas: "Arequipa feliz, joh patria amada!, / de la fortuna gloríate que esperas: / ya vuelve así a nosotros rectas luces / aquel Sol que ilustró tantas esferas". ${ }^{6}$

Una manifestación artística contemporánea a Travada, la ópera-serenata: Venid, venid, deydades, de fray Esteban Ponce de León, estrenada en 1749 en ocasión de la elevación del arequipeño Fernando Pérez de Oblitas a la sede episcopal de Asunción del Paraguay, confirmaría este nuevo interés en ocupar el espacio simbólico por parte de las élites arequipeñas. En esta obra, Arequipa y el Cusco se disputan alegóricamente la maternidad del obispo; Arequipa por

Arequipa, Fundación M. J. Bustamante de la Fuente y Universidad Nacional San Agustín, 1993, p. 108.

5 Ventura Travada, Suelo..., fol. 172.

6 Romance heroico endecasílabo del maestre de campo don Manuel Hermenegildo del Rivero (1747).

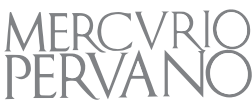


"ser madre primera" y Cusco por ser "madre segunda" al haberlo educado y tenido hasta el momento como rector de su seminario. Ante este dilema hacen comparecer a los dioses. El alegato de Arequipa se expresa:

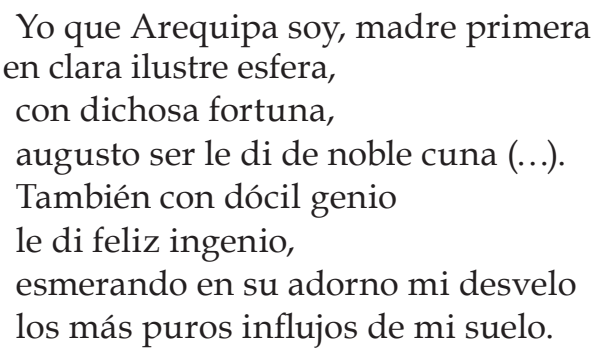

Finaliza con un coro exuberante y algo frenético: "Viva, viva mi Arequipa, / Y a su instancia ceda la razón. / Y entre sus timbres escrita, / la gloria de este blasón!"7. Si se tiene en cuenta que la obra fue estrenada en el Cusco, pues no es difícil imaginar cierto frenesí por posicionar las tardías y todavía escasas producciones culturales arequipeñas en un ámbito agonístico donde compitan con regiones con tradiciones más prestigiosas.

\section{¿Cómo era, entonces, la Arequipa de mediados del siglo XVIII?}

Contamos con la descripción de Jorge Juan y Antonio de Ulloa, marinos y científicos españoles, que tres años antes habían llegado al Perú oficialmente encargados de acompañar la famosa expedición científica de La Condamine, pero con el secreto designio de observar críticamente los territorios hispánicos de ultramar con fines reformistas. De 1748 data su Relación histórica del viaje a la América meridional hecho de orden a su majestad para medir algunos grados de magnitud de la tierra con otras varias observaciones astronómicas y físicas, aunque recogía informes de una década atrás. En el capítulo XII del primer libro se encuentra una descripción de la comarca. Juan y Ulloa observan que esta ciudad es:

[P]or su capacidad de las mayores, que se reconocen entra las que pueblan los vastos países del Perú: su planta es admirable por estar en llano; y a las ventajas que por ella logra, acompaña la bella disposición de las casas, siendo todas de piedra; y abovedadas, unas altas y otras bajas, aunque la mayor parte de estas últimas, ofrecen a sus habitantes viviendas muy desahogadas y cómodas, y a la vista con el exterior aparato un aspecto agradable: con esto anuncian el particular aseo y primor, que en lo anterior las adorna; siendo universal el cuidado de aquellos vecinos por esmerarle en la mayor decencia. ${ }^{8}$

\footnotetext{
7 Hemos tomado la versión ejecutada por el Ensamble Louis Berger, dirigido por Ricardo Massun, editada por Harmonia Mundi, de Arlés, en el 2001, en la colección Les chemins du baroque.

$8 \quad{ }^{7}$ Víctor Sánchez-Moreno, Arequipa colonial y las fuentes de su historia. Estudio crítico. Lima,
} 
La descripción de los dos marinos españoles enfatiza en la "alegría y fertilidad" de sus campos y la "excelencia del temperamento y sanidad del clima", 9 y reafirman la imagen cervantina de Arequipa de eterna primavera: "todo el año en la apacibilidad, y en la alegría vista, que los campos matizados de flores y vestidos de verde yerba ofrecen a los ojos una incansable primavera". ${ }^{10}$

Hasta este punto podemos anotar que la visión de Arequipa de Ulloa y Juan resulta alto lisonjera para la ciudad, si se considera que ambos personajes no eran criollos -y como lo demostraron en otros pasajes de su Relación y en las cáusticas Noticias secretas de América- no muy amigos de fantasías ni hipérboles que pudiesen oscurecer la perspectiva reformadora ilustrada que se preciaban de poseer. La Arequipa que encontraron era una ciudad comercial de provincias sin los blasones de una audiencia (como Chuquisaca) ni ser cabeza de reyno (como el Cusco o Lima) ni albergar abundancia de títulos de Castilla (como la villa de Moquegua o incluso Trujillo), pero próspera, ordenada, despojada del desorden de esclavos y ganapanes que orbitaban alrededor de ciudades nobiliarias. Es muy probable que una ciudad industriosa y relativamente moderna ${ }^{11}$ despertase la admiración de reformistas ilustrados españoles, críticos del viejo orden imperial y su supuesto mal funcionamiento, pero todavía imbuidos en la concepción tradicional hispánica del mundo, que los llevaba a no condenar las tradiciones ni costumbres de la sociedad arequipeña como supersticiosas, tenebrosas o vulgares, tal como lo harían algunos viajeros europeos posteriores, siendo el ejemplo más destacado el de Flora Tristán casi un siglo después.

Seguidamente los autores enumeran las instituciones administrativas, jurídicas y religiosas que tienen sede en la ciudad. Mencionan con detenimiento las actividades económicas de los corregimientos de la jurisdicción del obispado: Arequipa y su producción de trigo, granos y "ganados siempre gordos", Camaná con "crecidas porciones de burros", pero con sus minas de plata abandonadas, así como los recursos naturales y productivos de Condesuyos, Caylloma, Moquegua y Arica, que llegaban a un nivel de detalle y concisión en los datos verdaderamente admirable.

Así, podemos considerar a esta etapa histórica como el inicio del proceso de conquista del espacio simbólico por parte de las élites arequipeñas y sus brazos letrados en consonancia con el despertar económico y la importancia política que esta ciudad periférica empezaría a gozar en las últimas décadas del siglo

\footnotetext{
Aserprena, 1987, p. 106. Fragmentos significativos de la Relación referidos a Arequipa se encuentran recopilados en este libro entre las páginas 105 y 108.

$9 \quad$ Víctor SÁnchez-Moreno, Arequipa colonial..., p. 107.

10 Víctor Sánchez-Moreno, Arequipa colonial..., pp. 106-107.

11 Los edificios de Arequipa requerían constante refacción e incluso restauración: el terremoto más reciente había sido el de 1725, que, en palabras de Juan y Ulloa, "aunque (...) no fue tan general la desolación, padeció [la ciudad] lo bastante para que se venciesen a su esfuerzo los edificios grandes, y muchas de sus casas". (p. 107)
} 
XVIII. Para el siglo siguiente y durante buena parte del periodo republicano, esta conquista se extendería hacia el espacio político, con lo que Arequipa lograría desplazar al Cusco en importancia en el sur del Perú y se convertiría en lo que Basadre llamaría "una pistola apuntando al corazón de Lima". ${ }^{12}$

\section{Una realidad distinta: pobreza, vanidad y crímenes sonados}

Pero más allá de las disposiciones retóricas de los letrados arequipeños, la realidad era ciertamente más compleja. En 1734 el nombre de Arequipa considerado entonces ya famoso, como veremos- volvía a despertar la atención de un escritor metropolitano, pero en ánimo ciertamente distinto al lisonjero de un Miguel de Cervantes dos siglos atrás:

En Arequipa una Ciudad de gran pobreza en el Perú, y de tal vanidad en sus Vecinos, que por ella se dice aquel Proverbio: De Dones, pendones, y muchachos sin calzones. Sucedió, que llegando a apearse en la Posada cierto Religioso grave, vio un Mozuelo hecho andrajos, dixole: Ha Mancebo, tenme este Estrivo. Respondiole enfurecido: Ha Padre, sabe que habla con Don N. de tal y tal?, arrojándole millones de Apellidos; a que dixo el Religioso: Pues Señor Don Fulano de tal, y tal y tal, V. md. Se vista como Se llama, o Se llame como Se viste. ${ }^{13}$

Se trata de Bernardino Fernández de Velasco y Pimentel, duque de Frías, en su Deleyte de discreción y fácil escuela de agudeza, suerte de poliantea o antología de apólogos y máximas, seguidas de alguna enseñanza ingeniosa y moralizante. En el siglo siguiente, Zamácola, Pereyra y Ruiz y Ricardo Palma repetirían el proverbio, que iría convirtiéndose en un lugar común respecto a los arequipeños: su orgullo y austeridad o, visto desde otra perspectiva, su soberbia y tacañería/pobreza. Quizás esta supuesta "vanidad", que aún supervive en algunas manifestaciones de la idiosincrasia local, se origine en ese intento tardío de posicionarse simbólicamente ante urbes peruanas más antiguas, en un contexto geográfico y económico relativamente pobre, pero que sirvió para potenciar algunas características emprendedoras en los liderazgos arequipeños.

Esta misma élite procuraría a partir del periodo republicano desarrollar un modelo simbólico de virtud cívica y ciudadana que llegaría a tener cierto arraigo, incluso diríamos mítico, y que alcanzaría su expresión consumada en Arequipa de mi infancia, las memorias de Víctor Andrés Belaunde. Sin embargo su cohesión económica, su influencia política y, principalmente, su autoridad moral colapsarían a partir de 1970. Este colapso se reflejaría en un suceso escandaloso

\footnotetext{
12 Jorge BAsAdre, La multitud, la ciudad y el campo en la historia del Perú. $3^{\underline{a}}$ ed., Lima, Ediciones Treintaitrés \& Mosca Azul, 1980, p. 199.

13 Bernardino Fernández de Velasco y Pimentel, Deleyte de la discreción y fácil escuela de la agudeza, que en ramillete texido de ingeniosas promptitudes y moralidades provechosas... Madrid, Imprenta Real de la Gaceta, 1764, pp. 83-84. Tomamos la cita de la tercera edición.
} 
y criminal del que todavía se guarda memoria y que ocurrió a mediados de esa década.

Un interesante antecedente de aquella manifestación de vesania lo encontramos en el sonado caso del maestre de campo Juan Jiménez Lancho, alcalde de Arequipa en 1741 y 1752, de origen peninsular y tronco de numerosas familias del patriciado arequipeño por sus tres matrimonios.

El 30 de marzo de 1748, el deán de la catedral de Arequipa, Juan Bautista de Taborga, en nombre del obispo Juan Bravo del Rivero, se apercibía a declarar ante él, con amenaza de excomunión, a todos aquellos que supiesen algo de la conducta criminal de Jiménez Lancho, quien al parecer obligaba a sus esposas a testar a su favor antes de matarlas:

Malditos sean los dichos excomulgados de Dios y de su bendita Madre. Amén. Huérfanos se vean sus hijos y sus mujeres viudas. Amén. El sol se les obscurezca de día y la luna de noche. Amén. Mendigando anden de puerta en puerta no hallando quien bien les haga. Amén. Las plagas que envió Dios sobre el reino de Egipto vengan sobre ellos. Amén. Las maldiciones de Sodoma y Gomorra que por sus pecados los tragó vivos la tierra vengan sobre ellos. Amén. Con las demás maldiciones del Salmo Deus laudem y dichas las expresadas maldiciones lanzando las candelas en el agua, digan así como estas candelas mueren en esta agua, mueran las ánimas de los dichos excomulgados y desciendan al infierno con la de Judas Apóstata. Amén. ${ }^{14}$

Ante tan horrorosa amenaza acudieron varios testigos a declarar ante la corte eclesiástica -que, como es evidente, procesaba a Jiménez Lancho por el abuso del sacramento del matrimonio, pues le correspondería a la justicia civil procesarlo por los crímenes de sangre-, quienes refrendaron la denuncia original presentada por su yerno Felipe de Portú. Astutamente Jiménez Lancho adujo pobreza y ocultó sus bienes. Como apunta Bustamante, "[1]os numerosos descendientes de Jiménez Lancho ignoran probablemente los puntos que calzaba en materia de criminalidad su antepasado, que murió tranquilamente en su cama sin que se castigaran sus delitos". ${ }^{15}$ Pero no quedó ahí la infamia, en 1752, justo en el mismo año en que fallecía el obispo Bravo del Rivero, Juan Jiménez Lancho era nuevamente elegido alcalde, cuatro años después de las denuncias en su contra, y dejaba "numerosa y noble descendencia". ${ }^{16}$

La índole de este personaje, digno de figurar en alguna historia de la locura arequipeña junto con el hijo del fundador Garcí Manuel de Carbajal y

\footnotetext{
14 Manuel J. Bustamante de la Fuente, La monja Gutiérrez y la Arequipa de ayer y hoy. Lima, Gráfica Morsom, 1971, p. 29. Las cartas y los documentos de este caso curiosísimo los trae este recordado abogado y político arequipeño entre las páginas 26 y 30 de su libro.

15 Manuel J. Bustamante de la Fuente, La monja Gutiérrez..., p. 30.

16 Santiago Martínez, Alcaldes de Arequipa. Desde 1939 a 1946. Arequipa, Tipografía Acosta, 1946, p. 199.
} 
el rey de los camanejos Pedro Rossell, por citar solo a algunos, todavía queda envuelta en el misterio. Ante la venalidad e inacción de un poder instructor en materia penal que correspondía, en primera instancia, al cabildo en primera instancia, probablemente copado por sus cómplices, la única institución que intentó hacerle frente fue la Iglesia, presidida en aquel momento por un prelado bastante singular, el limeño Juan Bravo del Rivero (1685-1752), obispo de Santiago de Chile entre 1734 y 1743 y de Arequipa entre 1743 y su muerte.

El berylo o berilio, aludido por Travada, en un simbolismo lapidario, tiene una significación adecuada a su poseedor: "prelado ejemplar: teólogo profundo: jurisconsulto consumado: imitador de los Ambrosios en lo integérrimo: de los Villanuevas en lo desinteresado y limosnero, y de los Mogrovejos en lo celoso y penitente". ${ }^{17}$ Murió en olor de santidad.

No parece haber sido este elogio una mera manifestación de aulicismo, pues además de ser un gran benefactor de la ciudad, Bravo del Rivero fue un reformador sagaz y valiente, tanto de las costumbres del clero como del laicado, pues manifestó también lo que ahora llamaríamos sensibilidad social:

Lo primero que hizo en Arequipa fue suspender las licencias del clero para decir misa y confesar, designando un plazo limitado para probar la suficiencia, prueba que practicaba personalmente. Reformó asimismo las costumbres de los eclesiásticos: combatió el lujo de las señoras en sus vestidos e hizo sangrienta guerra a los contratos usurarios, publicando terribles edictos para extirparlos y castigando con la severidad de los cánones a los que los celebraban. Visitó todo el obispado, llevando vestidos de algodón y lana para los pobres, que repartía según las necesidades de cada pueblo, sin causar ningún gravamen a los párrocos. ${ }^{18}$

Podría imaginarse una contraposición entre ambas figuras, larger than life, a su modo; por un lado, el 'gran señor' indiano, arbitrario y demencial, con rasgos semejantes a figuras legendarias como Lope de Aguirre o La Quintrala, por otro, el obispo austero valiente, que no hace concesiones ante los poderes fácticos, a veces extraordinariamente opresivos, a la hora de proclamar y defender la justicia y los valores evangélicos. ¿La lucha entre el alcalde y el obispo tomaría los visos de la de un Tomás Beckett contra Enrique II? Algo ocioso es pensarlo: la penuria documental que ha diezmado incluso los archivos oficiales no nos permite conocer las memorias personales, las cartas privadas ni los diarios que podrían dar cuenta de más detalles de este singular caso. Quizás también, como todavía ocurre, haya existido alguna mano interesada en ocultar estos hechos, por un malentendido celo familiar.

17 Así dice la inscripción en la cartela de su retrato en la sacristía del monasterio de Santa Rosa. Ver Mariano Ambrosio Cateriano, "Memorias de los Iltmos. Srs. Obispos de Arequipa (1908)", en Obras. Arequipa, Universidad Nacional San Agustín, 1998, pp. 340-341.

18 Mariano Ambrosio Cateriano, “Memorias...", p. 339. 


\section{Conclusión}

La Arequipa de mediados del siglo XVIII se aprestaba a jugar un papel importante en la nueva configuración del reino peruano que empezaba a desenvolverse en vísperas de las reformas borbónicas. Esta posición expectante se refleja en la aparición de un discurso letrado propio, tardía si se compara con la de las cabezas del reyno (Cusco y Lima), pero que trata de compensar sus debilidades con una hiperbólica exaltación barroca y un orgullo erudito singular.

Por otro lado, la ciudad moderna y ordenada que Jorge Juan y Ulloa creen encontrar a inicios de la década de 1740 es la misma donde reina todavía la impunidad ante los graves crímenes del alcalde Jiménez Lancho, en una dimensión para nada diferente a los graves abusos y corrupción que ambos viajeros observaron en distintos puntos del reino. Ambos aspectos eran, como sabemos, reales: por un lado, la ciudad pujante y nueva con un liderazgo perseverante y frugal y, por otro, el estrecho pueblo de escasos recursos económicos y simbólicos, donde el poder, revestido de múltiples caretas de respetabilidad, siempre está dispuesto a formar argollas de abuso e impunidad casi impenetrables.

Todas estas claves de interpretación deberán servir para ulteriores estudios sobre la historia de las mentalidades en Arequipa, en los momentos previos a las conmociones independentistas, en el proceso de la construcción de una nueva identidad republicana a lo largo del siglo XIX y aun en nuestros días. 